\section{Role of leptin in fat regulation}

SIR - Leptin administration reduces body weight and adipose tissue mass. However, the weight loss observed cannot be completely attributed to decreased food intake ${ }^{1-3}$. In rodents, brown adipose tissue is the primary thermogenic organ, and it has become increasingly clear that brown adipose tissue is significant in regulating body composition. Brown adipose tissue can be activated by acclimation to cold temperatures and by excess food intake. These effects appear to be mediated through noradrenergic stimulation $^{4-6}$. Indeed, early studies demonstrated defective thermogenesis in genetically obese $(o b / o b)$ and diabetic $(d b / d b)$ mice $^{7,8}$.

Recently, we have shown that leptin seems to be a sensor of adipocyte mass, and that treatment with a thermogenic $\beta_{3}$-adrenergic receptor agonist reduces both adipose tissue mass and leptin expression ${ }^{9}$. Therefore, we hypothesized that leptin's role in regulating fat mass might include signalling the sympathetic nervous system to increase thermogenesis and energy expenditure in brown adipose tissue as fat mass increases. In this case, white adipose tissue mass would be regulated by brown adipose tissue activity through leptin-stimulated sympathetic outflow.

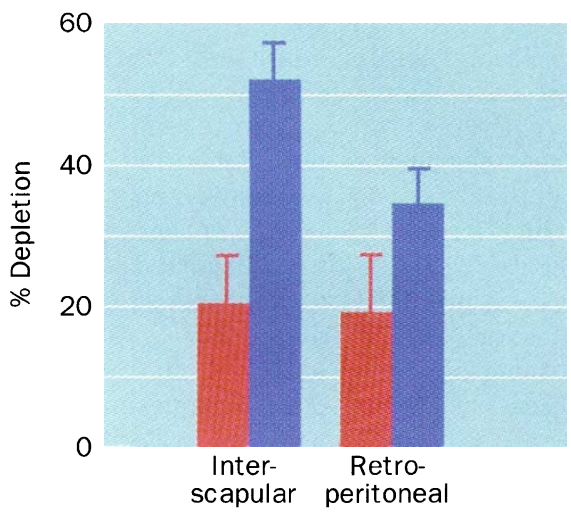

FIG. 1 Effect of leptin on the rate of noradrenaline depletion in brown and white adipose tissue depots after synthesis inhibition with AMPT. Groups of 12 mice were injected i.p. with either $100 \mu \mathrm{l}$ phosphate-buffered saline (PBS; red columns) or $100 \mu \mathrm{l}$ PBS containing $40 \mu g$ recombinant leptin (blue columns). Data shown are the average of two independent experiments. Per cent depletion was calculated relative to the time 0 value. Results are expressed as mean \pm s.e.m. for each group. Results were analysed by 3-way ANOVA (fat pad $\times$ treatment $\times$ time), followed by a 2-way ANOVA on specific fat pads (treatment $\times$ time) and post-hoc Fisher's protected LSD using SuperANOVA; $n=12$ mice per group. Asterisk indicates $P<0.04$.
We determined sympathetic outflow by assessing noradrenaline turnover after blockade of catecholamine synthesis with the tyrosine hydroxylase inhibitor $\alpha$ methyl-p-tyrosine (AMPT) ${ }^{10-12}$. Twentyfour female C57BL/6J $(o b / o b)$ mice at $5-6$ weeks of age were given either $40 \mu \mathrm{g}$ recombinant murine leptin prepared as described $^{2}$ or saline by intraperitoneal injection 2 hours after the start of the dark cycle (lights off at $1600 \mathrm{~h}$ ). The mice were fasted for the 12 hours of the light cycle before the experiment, and then each received a weighed amount of mouse chow. Food intake was measured for 2 hours after leptin or saline administration. Animals were then given an intraperitoneal injection of AMPT (250 $\mathrm{mg}$ per kg body weight). Half the animals (12 per treatment group) were killed immediately and the second half 4 hours later. These time points were based on previous studies establishing the linearity of the fall in noradrenaline content in murine tissues after inhibition of synthesis ${ }^{12}$. Interscapular brown and retroperitoneal white adipose tissue was collected for catecholamine analysis.

Leptin administration resulted in a selective increase in noradrenaline turnover to interscapular brown adipose tissue, but did not significantly affect noradrenaline turnover in retroperitoneal white adipose tissue (Fig. 1). There were no differences in food intake between the groups during the 2-hour period after leptin injection (Fig. 2). This effect of leptin on noradrenaline release is consistent with our hypothesis that thermogenesis in brown adipose tissue may be an important mechanism by which leptin regulates body composition, and could be responsible for the increased metabolic rate and core temperature reported after chronic leptin administration ${ }^{1-3}$.

Indeed, it is possible that the development of obesity in a transgenic mouse with decreased brown adipose tissue, described by Lowell and colleagues ${ }^{5}$, may be related to the inability of leptin to signal thermogenesis in this system. Because many forms of obesity have been associated with increased leptin levels ${ }^{13-15}$, it has been argued that 'leptin resistance' may be involved in obesity syndromes. Another possibility is that

\footnotetext{
1. Pelleymounter, M. A. et al. Science 269, 540-543 (1995).

2. Halaas, J. L. et al. Science 269, 543-546 (1995).

3. Campfield, L. A. et al. Science 269, 546-549 (1995).

4. Rothwell, N. J. \& Stock, M. J. Nature 281, 31-35 (1979).

5. Lowell, B. B. et al. Nature 366, 740-742 (1993).

6. Kopecky, J., Clarke, G., Enerback, S., Spiegelman, B \& Kozak, L. P. J. clin. Invest. 96, 2914-2923 \& Kozak,

7. Trayhurn, P. \& Thurlby, P. L. Pflügers Arch. 373, 189-193 (1978)

8. Thurlby, P. L. \& Trayhurn, P. Br. J. Nutr. 42, 377-385
} (1979).

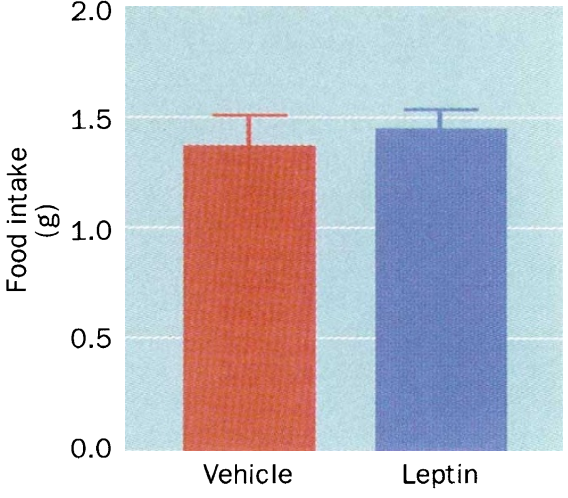

FIG. 2 Food intake in the 2-h period after i.p. injection of leptin or PBS vehicle. The effects of leptin administration are compared with those of vehicle (PBS). Food intake was measured for individual mice during the 2-h treatment period before AMPT injection and analysis of catecholamine levels. Data shown are mean \pm s.e.m. for each group.

some obesity results from the failure of brown adipocytes to respond appropriately to leptin-induced sympathetic activity. In at least one model of dietinduced obesity, brown adipocytes failed to respond adequately to sympathetic stimuli $^{16}$.

In summary, we detected increased sympathetic outflow in response to leptin without changes in food intake during a 2-hour treatment period. Therefore, enhanced energy utilization as well as decreased food intake together may account for the weight-reducing effects of leptin.

Sheila Collins ${ }^{\star \dagger}$

Cynthia M. Kuhn ${ }^{\dagger}$

Ann E. Petro*

Andrew G. Swick ${ }^{\S}$

Boris A. Chrunyk"

Richard S. Surwit ${ }^{*}$

Departments of ${ }^{*}$ Psychiatry and Behavioral Sciences and ${ }^{\dagger}$ Pharmacology, and

${ }^{*}$ The Sarah W. Stedman Center for

Nutritional Studies,

Duke University Medical Center, Durham,

North Carolina 27710, USA

and

Departments of ${ }^{\mathcal{S}}$ Metabolic Diseases and "Molecular Sciences,

Pfizer Central Research,

Groton, Connecticut 06340, USA

9. Collins, S. \& Surwit, R. S. J. biol. Chem. 271 (16) 9437-9440 (1996).

10. Spector, S., Sjoerdsma, A. \& Udenfriend, S. J. Pharmac. exp. Ther. 147, 86-95 (1965).

11. Yoshida, T., Nishioka, H., Nakamura, Y. \& Kondo, M. Metabolism 33, 1060-1063 (1984).

12. Kuhn, C. M., Surwit, R. S. \& Feinglos, M. N. Life Sci. 58, 661-666 (1994).

13. Maffei, M. et al. Proc. natn. Acad. Sci. U.S.A. 92, 6957-6960 (1995).

14. Ogawa, Y. et al. J. clin. Invest. 96, 1647-1652 (1995)

15. Considine, R. V. et al. J. clin. Invest. 96, 2720-2728 (1995).

16. Collins, S. et al. Int. J. Obesity 18 (Suppl 2), 75 (1994) 